\title{
A Study on Diagnostic Accuracy of Cervical Pap Smear by Correlating with Histopathology in a Tertiary Care Centre
}

\author{
Rachana L Y, S.S. Hiremath*, Prabhu M H, S .S Inamdar and Venkata Kalyan Nunna \\ Department of Pathology, S. N.Medical College, Bagalkot, Karnataka,India
}

\begin{abstract}
Objective: Analysis of various lesions detected on Cervical Pap smears and correlate it with histopathology to detect the diagnostic accuracy of Pap smears in detection of cervical lesions.

Methodology: The present study is a prospective study conducted from December 2015 to May 2017 for a period of 18 months which included 83 cases. All these patients underwent screening procedure with cervical smears and were directed for colposcopic guided biopsy.

Results: In the present study Pap smears showed sensitivity of $96.42 \%$, specificity of $70.37 \%$ and diagnostic accuracy of $87.95 \%$.

Conclusion: Pap smear being minimally invasive showed significant correlation with Colposcopic directed biopsy. Pap smear still remains ideal screening procedure for early detection of cervical lesions.
\end{abstract}

\section{Keywords: ?Cervical Pap Smear, Sensitivity, Specificity, Diagnostic Accuracy}

\section{Introduction}

Cervical cancer is the second most common cancer in females worldwide and major cause of morbidity and mortality. ${ }^{[1]}$ Cervical cancer is preventable and cervical screening in many ways is an ideal screening test. ${ }^{[2]}$ Biopsy to confirm the presence of cervical cancer has long been used, but the more recent use of colposcopic directed biopsy on patients with abnormal Pap smear has allowed the recognition and treatment of cervical lesion at much earlier stage. ${ }^{[3]}$ Ideally, all patients with abnormal Pap findings should be subjected for colposcopy. ${ }^{[4]}$ Colposcopy used with Pap smear complement each other in detecting cervical lesion at earliest followed by histopathology which forms gold standard in confirming the diagnosis. ${ }^{[5]}$

Hence, this study was undertaken. The objective of this study was analysis of the cervical pap smears for various abnormalities of cervix and co-relating cytology with histopathology.

\section{Methodology}

This is a hospital based 18 months prospective study conducted from December 2015 to May 2017 in S. Nijalingappa Medical College, Bagalkot, Karnataka after taking approval from Institutional Ethical Committee. 83 cases attending the hospital with the complaints of white discharge per vagina, pain abdomen and other gynecological complaints were included in the study .The following were the inclusion criteria :1) Sexually active women in reproductive age group (20-70 years).2)Women with symptoms of white discharge per vagina, post coital, intermenstrual bleeding and post menopausal bleeding.3) Women who had undergone cytological screening of cervix. The following were the exclusion criteria : 1) Known case of carcinoma cervix.2)Patients undergoing chemotherapy and radiotherapy3) Pregnant women.

Written and informed consent was taken from all the patients after a brief explanation of the procedure. A careful history including demographic data like age, socioeconomic status, education, parity and age at marriage of the patient was taken. General examination and systemic examination was done. Information is noted on pretested proforma. Prepared Pap smear slides were received, fixed in 95\% ethyl alcohol and ether. All the women were subjected to colposcopy and cervical biopsy was taken. Colposcopic directed biopsy specimens were received in $10 \%$ formalin fixative. The prepared Pap smear slides were then stained according to the Conventional PAP technique and examined under a light microscope. The cytological interpretation of the smears was made according to the Bethesda system 2014.

Colposcopy-directed biopsies were processed, histopathological slides prepared and stained with hematoxylin and eosin and examined under a light microscope. Biopsy results were categorized as chronic cervicitis, Cervical Intraepithelial Neoplasia I (CIN I), CIN II, CIN III, Carcinoma in situ, Squamous cell carcinoma (SCC) and Adenocarcinoma according to WHO. Statistical analysis was Carried out for calculating sensitivity, specificity and positive and negative predictive value of Pap smear by correlating with histopathological examination. 


\section{Results}

In the prospective study conducted from December 2015 to May 2017 for a period of 18 months 83 cases were analyzed and results are as shown in Tables 1 to 5 .

Table 1: Presenting complaints of patients in present study.

\begin{tabular}{|l|c|c|}
\hline Presenting complaints & No. of cases & Percentage \\
\hline Pain abdomen & 20 & 61.4 \\
\hline White discharge per vagina & 51 & 2.4 \\
\hline Pain abdomen and white discharge per vagina & 02 & 9.6 \\
\hline Irregular bleeding & 08 & 2.4 \\
\hline Itching over genitals & 02 & 100 \\
\hline Total & 83 & 2 \\
\hline
\end{tabular}

Table 2: Cytological Interpretation in present study as per Bethesda System 2014 classification.

\begin{tabular}{|l|c|c|}
\hline Bethesda 2014 & No. of cases & Percentage \\
\hline NILM & 21 & 25.30 \\
\hline ASCUS & 17 & 6.02 \\
\hline ASC-H & 05 & 26.50 \\
\hline LSIL & 22 & 10.84 \\
\hline HSIL & 09 & 6.02 \\
\hline SCC & 05 & 4.81 \\
\hline AGC & 04 & 100 \\
\hline Total & 83 & 2 \\
\hline
\end{tabular}

Table 3: Histopathological diagnosis of the cases.

\begin{tabular}{|l|c|c|}
\hline Histopathological diagnosis & No. of cases & Percentage \\
\hline Chronic cervicitis & 27 & 32.53 \\
\hline CIN I & 27 & 16.86 \\
\hline CIN II & 14 & 4.81 \\
\hline CIN III & 04 & 6.02 \\
\hline Squamous cell carcinoma (Well differentiated) & 05 & 4.81 \\
\hline Squamous cell carcinoma (Moderately differentiated) & 04 & 2.40 \\
\hline Squamous cell carcinoma (Poorly differentiated) & 02 & 100.00 \\
\hline Total & 83 & 2 \\
\hline
\end{tabular}

\section{Discussion}

Premalignant and Malignant cervical lesions can be detected in Pap smears. Low grade squamous intraepithelial lesion (Koilocytosis or flat condyloma or CIN I) represents 
Table 4: Co-relation of Cervical cytology with histopathologic diagnosis.

\begin{tabular}{|c|c|c|c|c|c|}
\hline \multirow{2}{*}{ Cytology } & \multicolumn{5}{|c|}{ Histopathology } \\
\hline & Chronic cervicitis & CIN I & CIN II \& CIN III & scc & TOTAL \\
\hline NILM & 19 & 02 & 00 & 00 & 21 \\
\hline ASCUS & 03 & 11 & 03 & 00 & 17 \\
\hline ASC-H & 00 & 01 & 02 & 02 & 05 \\
\hline AGC & 03 & 00 & 01 & 00 & 04 \\
\hline LSIL & 02 & 12 & 07 & 01 & 22 \\
\hline HSIL & 00 & 01 & 05 & 03 & 09 \\
\hline $\mathrm{SCC}$ & 00 & 00 & 00 & 05 & 05 \\
\hline Total & 27 & 27 & 18 & 11 & 83 \\
\hline
\end{tabular}

Table 5: Comparison of statistical parameters of Pap smears:

\begin{tabular}{|c|c|c|c|c|c|}
\hline Studies & Sensitivity & Specificity & PPV & NPV & $\begin{array}{c}\text { Diagnostic } \\
\text { accuracy }\end{array}$ \\
\hline Present study (2017) & $96.42 \%$ & $70.37 \%$ & $87.09 \%$ & $90.40 \%$ & $87.95 \%$ \\
\hline Chaudhary et al (2016) & $25.40 \%$ & $99.27 \%$ & $94.12 \%$ & $74.32 \%$ & $80.5 \%$ \\
\hline Ashmita et al (2013) & $19.51 \%$ & $83.33 \%$ & $80.00 \%$ & $23.26 \%$ & $86.54 \%$ \\
\hline Malur et al (2009) & $41.66 \%$ & $81.2 \%$ & $86.21 \%$ & $78.26 \%$ & $80 \%$ \\
\hline Jain et al (2010) & $78 \%$ & $91.1 \%$ & $26.9 \%$ & $11.3 \%$ & $73.2 \%$ \\
\hline
\end{tabular}

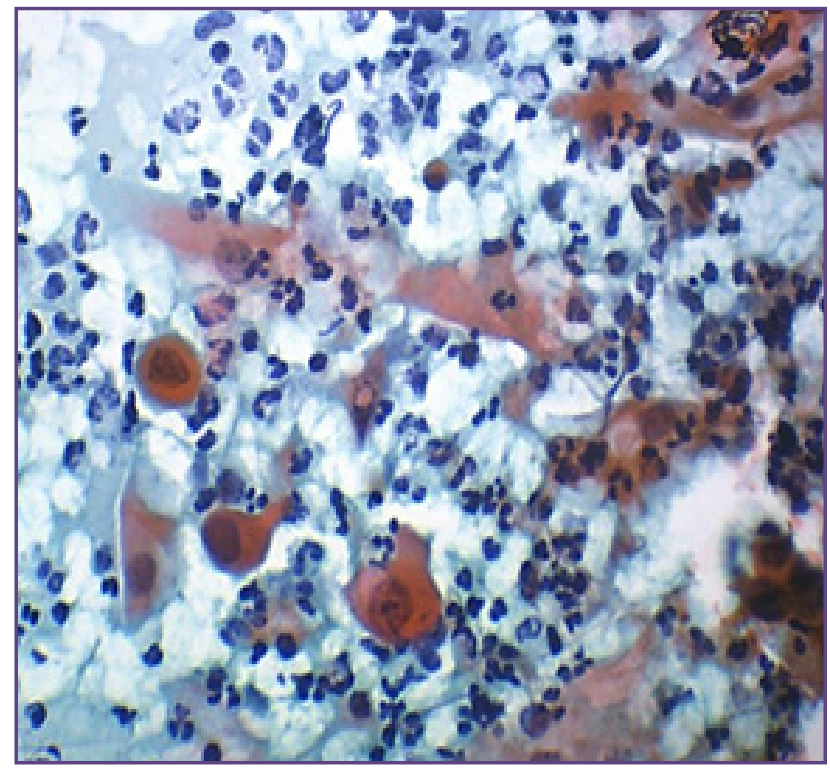

Fig. 1: High grade squamous Intraepithelial lesion cells with enlarged, hyperchromatic nuclei and irregular nuclear outline, (PAP stain, $400 \mathrm{X}$ ).

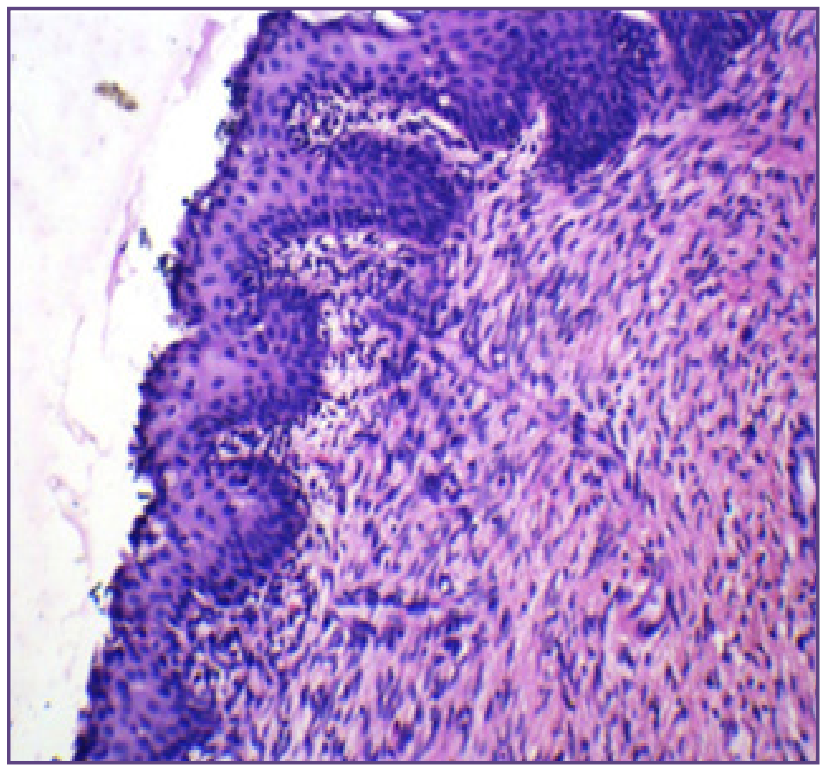

Fig. 2 :Section showing Chronic cervicitis with Severe dysplasia - CIN III, (H \& E Stain , 100 X). 


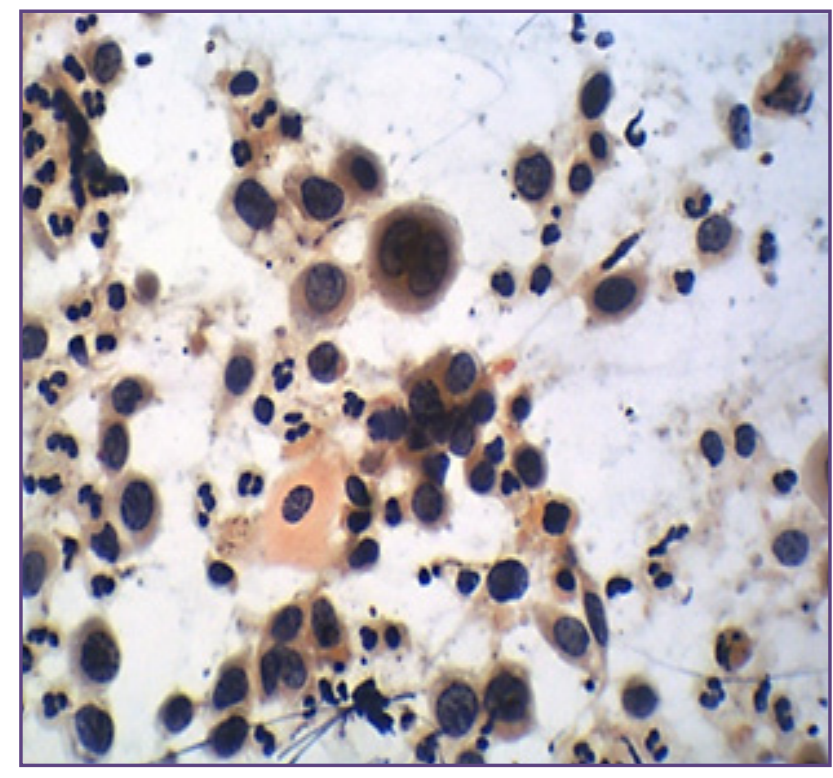

Fig. 3 : Pap smear of cervix showing Invasive squamous cell carcinoma .(PAP Stain, $400 \mathrm{X}$ ).

the clinical and morphological manifestation of productive HPV infection. It is characterized by proliferation of basal/ parabasal like cells that may be minimal but at most extends no more than one-third of the way up the epithelium. Mitotic activity is confined to this zone. Upper three -quarters to two thirds of the epithelium, the cells differentiate and gain cytoplasm however nuclear enlargement persists with nuclear hyperchromasia and nuclear membrane irregularities. Often there is development of a well defined halo like vacuole around the nucleus, this change along with cytoplasmic change is termed as koilocytosis, koilocytotic atypia or HPV cytopathic effect. ${ }^{[6]}$ High-grade squamous Intraepithelial lesions includes CIN II, CIN III. There is proliferation of squamous cells most frequently in the zone of metaplasia and near the squamo-columnar junction. In CIN II there is maturation present in upper half of the epithelium with nuclear atypia persisting to the surface. Nuclear abnormalities are more marked than in CIN I and extend further through the epithelium. Mitotic figures are present and are confined to the basal two-thirds of the epithelium. Abnormal forms may be seen. In CIN III there is maturation which maybe absent or confined to the superficial third of the epithelium. Nuclear abnormalities are marked throughout most of the thickness of the epithelium. Mitotic figures are numerous and are found at all levels of the epithelium. Abnormal mitosis are frequent. ${ }^{[7]}$

According to the international Committee on histological Terminology for lesions of the uterine cervix, " any lesion in which the epithelial formations invade the underlying

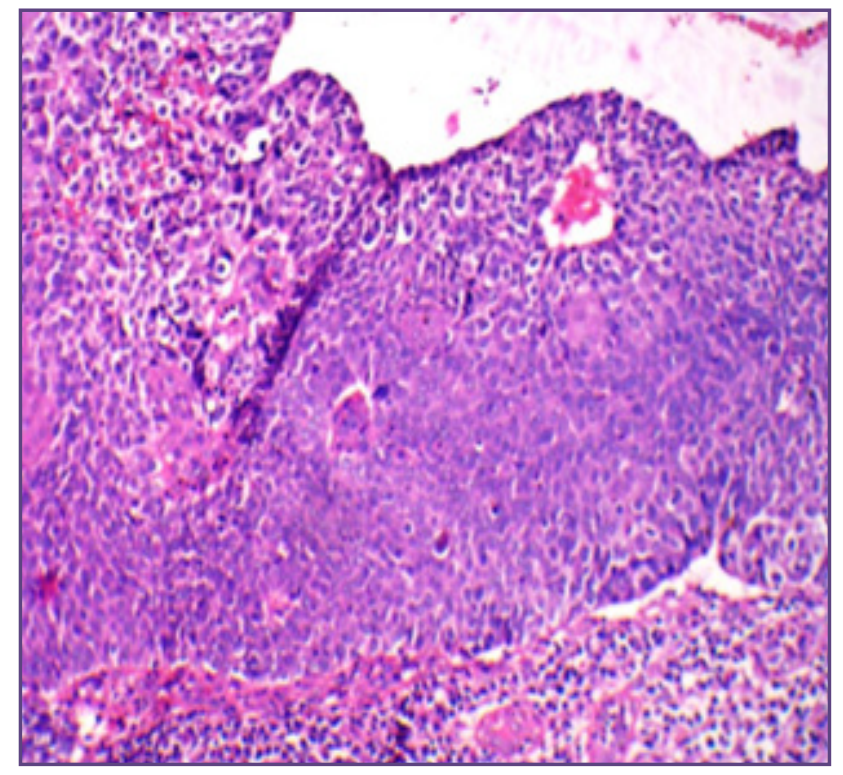

Fig. 4 : Section showing Poorly differentiated invasive squamous cell carcinoma (H \& E Stain, 100 X).

stroma by infiltration or destruction is to be classified as invasive carcinoma." A modification of the Border's method based on the degree of differentiation is currently the most widely used histologic grading system. According to this method squamous cell carcinoma are graded as well differentiated (grade I), moderately differentiated (grade II) and poorly differentiated (grade III). Most common is moderately differentiated squamous cell carcinoma. ${ }^{[7]}$

Out of 83 cases most common age group which was affected was found to be in the range of $31-40$ years, similar to the study conducted by Algotar K et al. ${ }^{[8]}$ The age group in which carcinoma cervix was reported was of higher age group. Most common presenting compliant in our study was white discharge per vagina similar to the Chaudhary et al. ${ }^{[1]}$ Other complaints being pain abdomen and irregular bleeding.

Cervical smear analysis showed higher number of Low grade intraepithelial lesion (LSIL) cases comprising $26.50 \%$ of case, followed by Negative for intraepithelial malignancy (NILM) accounting for $25.30 \%$ cases. We reported Atypical squamous cells of undetermined significance (ASCUS) in $20.48 \%$ cases, Atypical squamous cells cannot exclude an HSIL (A SC-H ) in $6.02 \%$ cases, High grade squamous intraepithelial lesion (HSIL) in $10.84 \%$, Squamous cell carcinoma (SCC) in $6.02 \%$ cases and Atypical glandular cells (AGC) in $4.81 \%$ of cases. On Histopathological examination chronic cervicitis was found in $32.53 \%$ cases, CIN I in $32.53 \%$, CIN II in 16.86 $\%$, CIN III in $4.81 \%$ cases and 11 cases were confirmed to have malignancy. 
Cervical smear analysis showed higher number of Low grade squamous intraepithelial lesion (LSIL) cases comprising $26.50 \%$ of cases with the cells in singles or in clusters with large cells having fairly abundant mature well defined cytoplasm with nuclear enlargement of more than 3 times the area of normal intermediate nuclei with coarsely granular chromatin with some cells having binucleation inconspicuous nucleoli and koilocytosis, followed by Negative for intraepithelial malignancy (NILM) with the smears displaying normal cellular elements that is superficial cells with pyknotic nucleus abundant eosinophilic cytoplasm, few intermediate cells having slightly larger nuclei compared to the superficial cells and abundant amount of cyanophilic cytoplasm accounting for $25.30 \%$ cases. We reported Atypical squamous cells of undetermined significance (ASCUS) in the smears showing few cells with features of LSIL and cellular changes with nuclear enlargement 2.5-3 times of normal intermediate cell, slightly increased ratio of nuclear to cytoplasmic area, and minimal nuclear hyperchromasia, and irregularity in chromatin distribution and nuclear membrane abnormality, with these features ASCUS was diagnosed in $20.48 \%$ cases. Atypical squamous cells cannot exclude an HSIL (ASC-H) was interpreted in the smears with the cells in singles or in small groups and individual cells were of the size of metaplastic cells with the nuclei of about $1.5-2.5$ times that of normal cells and increased nuclear to cytoplasmic ratio was approximating of that of High grade squamous intraepithelial lesion (HSIL) in $6.02 \%$ cases. HSIL with smears showing small and less mature cells, scant cytoplasm either as single or in syncytial aggregates with high nuclear cytoplasmic ratio, nuclear membrane irregularity and hyperchromasia coarsely granular evenly distributed chromatin was found in $10.84 \%$, Squamous cell carcinoma (SCC)was interpreted in $6.02 \%$ cases with the features of isolated cells and few clusters with marked variation in cellular size and shape with dense orangeophilic cytoplasm and increased nuclear cytoplasmic ratio, irregular nuclear membrane having coarsely granular irregularly distributed chromatin with macronucleoli with few cases associated with hyperkeratosis and parakeratosis. and smears with Atypical glandular cells (AGC) showed crowded sheets of cells with distinct cell border having abundant cytoplasm but increased nuclear to cytoplasmic ratio and enlarged nucleus up to $3-5$ times of normal endocervical nuclei with mild nuclear hyperchromasia mild chromatin irregularity and some cells showed nucleoli in $4.81 \%$ of cases. On Histopathological examination chronic cervicitis was found in $32.53 \%$ cases, CIN I in $32.53 \%$, CIN II in 16.86
$\%$, CIN III in $4.81 \%$ cases and 11 cases were confirmed to have malignancy. As with the other studies, the percentage of carcinoma was lower than the percentage of dysplasia in present study. With the sensitivity, specificity, positive predictive value, negative predictive value and diagnostic accuracy of $96.42 \%, 70.37 \%, 87.09 \%, 90.47 \%$ and $87.95 \%$ respectively Pap smear definitely showed a significant correlation with gold standard histopathology, which was comparable with the other studies Chaudhary et $\mathrm{a}^{[1]}$, Ashmita et al ${ }^{[9]}$, Malur et a ${ }^{[10]}$ and Jain et $\mathrm{a}^{\left[{ }^{[11]}\right.}$ as shown in Table 5.

\section{Conclusion}

Pap smear is an ideal screening procedure being minimally invasive, cost effective and accurate enough to demonstrate pre-malignant and malignant lesion of cervix. Complimentary to the Pap smears is the colposcopy which helps in visualization and aid us in identifying exact site for biopsy to be taken for histopathological diagnosis. With this study we conclude that there is definitely a significant correlation between Pap smear and histopathology and hence forth continues to be ideal procedure to identify the cervical lesion and initiate the therapy.

\section{Acknowledgement}

The authors would like to thank the patients for the support. We also thank the staff of Department of Pathology and Department of Obstetrics \& Gynaecology, S Nijalingappa Medical College, Bagalkot Karnataka for their support.

\section{References}

1. Chaudhary RD, Inamdar SA, Hariharan C. Correlation of diagnostic efficacy of unhealthy cervix by cytology, colposcopy and histopathology in women of rural areas. Int J Reprod Contracept Obstet Gynecol 2014;3:213-8.

2. Saha R, Thapa M. Correlation of cervical cytology with cervical histology. Kathmandu Univ Med J Cytol Histol 2010;3:222-4.

3. Malpani G et al. Cervical Pap smear study and detection of abnormal epithelial lesions and determination of its accuracy by cytohistological correlation in patients of tertiary care teaching hospital in central India. Int J Reprod Contracept Obstet Gynecol 2016;5(7):2312-16.

4. Barut MU, Kale A, Kuyumcuoglu U, Bozkurt M, Agacayak E, Ozekinci S et al. Analysis of Sensitivity, Specificity and Positive and Negative Predictive Values of Smear and Colposcopy in Diagnosis of Premalignant and Malignant Cervical lesions Med Sci Monit 2015;21:3860-7

5. Krishnegowda S, Veena MS. Efficacy of colposcopy technique with Pap smear and histology in screening of cervical lesions. Int J Reprod Contracept Obstet Gynecol 2014;3(3):696-702. 
6. Witkiewicz AK, Wright TC, Ferenczy A, Ronnett BM, Kurman RJ. In: Kurman RJ, Ellenson LH, Ronette BM, editors. Blaustein"s Pathology of the Female Genital Tract. 6th ed. New York: Springer; 2011:253-95

7. Kurman RJ, Carcangiu ML, Herrington CS, Young $\mathrm{RH}$, editors. WHO Classification of Tumors of Female Reproductive Organs. 4th ed. Lyon: IARC 2014: 169-206.

8. Algotar K, Nalwade A, Sachdev S. Predictive value of colposcopy in cervical cancer screening. Bombay Hosp J 2004;4603:1-9.

9. Ashmita D, Shakuntala PN, Rao Sr, Sharma SK, Geethanjali
S. Comparison and correlation of Pap smear, Colposcopy and histopathology in symptomatic women and suspicious looking cervix in tertiary hospital care centre. Int $\mathrm{J}$ Health Sci Res. 2013;3:50-9

10. Malur PR, Desai BR, Naita D, Geeta D, Bhavana S, Pallavi G. Sequential screening with cytology and colposcopy in detection of cervical neoplasia. J South Asian Feder Obst Gynae 2009;1:45-8.

11. Jain V, Vyas AS. Cervical Neoplasia-CytoHistological Correlation (Bethesda System) A Study of 276 Cases. J Cytol Histol 2010;1:106.

*Corresponding author:

Dr. S.S. Hiremath, Professor, Department of Pathology, S.NijalingappaMedical College, Bagalkot, Karnataka,India

Phone: +919880199316

Email: jjmmcpathology@gmail.com

Financial or other Competing Interests: None. 